\title{
Profile of Polycythemia Vera in Campus Teaching Hospital of Lome - Togo
}

\author{
Padaro Essohana ${ }^{1,4}$, *, Kueviakoe Irenee Messanh Delagnon ${ }^{1,2,4}$, Layibo Yao ${ }^{1,4}$, Kolou Malewe ${ }^{1,4}$, \\ Agbetiafa Kossi $^{1,4}$, Stephane Giraudier ${ }^{3}$, Segbena Akuete Yvon ${ }^{1,4}$ \\ ${ }^{1}$ Hematology, Campus Teaching Hospital of Lome, Lome, Togo \\ ${ }^{2}$ Hematology, Sylvanus Olympio Teaching Hospital of Lome, Lome, Togo \\ ${ }^{3}$ Biological Hematology Service, APHP Henri Mondor, University Paris XII, Creteil, France \\ ${ }^{4}$ Faculty of Health Sciences, University of Lome, Lome, Togo
}

Email address:

padarojustin@yahoo.fr. (P. Essohana), essohanapadaro@gmail.com (P. Essohana)

\section{To cite this article:}

Padaro Essohana, Kueviakoe Irenee Messanh Delagnon, Layibo Yao, Kolou Malewe, Agbetiafa Kossi, Stephane Giraudier, Segbena Akuete Yvon. Profile of Polycythemia Vera in Campus Teaching Hospital of Lome - Togo. Cancer Research Journal. Vol. 4, No. 1, 2016 , pp. $24-27$. doi: 10.11648/j.crj.20160401.13

\begin{abstract}
Objective: To describe the clinical, epidemiological and biological profile of polycythemia vera. Patients and methods: This is a descriptive study done from May to October 2014 witch included 13 patient who had been treated since 2007 at Campus Teaching Hospital of Lomé for polycythemia vera. The research of JAK2 V617Fmutation by PCR was been done inmolecular biologylaboratory of the Henri Mondor Hospital at Creteil in France. Results: The annual prevalence of polycythemia vera is about 2.16 new cases. The average age of patients was 46,7 years with ranges from 31 to 65 years. There were 9 men and 4 women. The most frequent factor of finding was the fortuitous ones (23\%). Most clinical signs represented were headache $(69.2 \%)$, skin érythroses $(53.8 \%)$ and paresthesia $(30.8 \%)$. The average value of hemoglobin, hematocrit, the number of white blood cells and platelets in our patients with polycythemia who had positive JAK2V617F was respectively: $198 \mathrm{~g} / \mathrm{L} \pm 44 ; 62.7 \pm 4.4 \% ; 9.8 \mathrm{G} / \mathrm{L} \pm 4.3,630.4 \mathrm{G} / 1 \pm 367.4$. Those Who didn't had JAK2mutation, had respectively: $179 \mathrm{~g} / \mathrm{L} \pm$ 13.3; 59,0\% $\pm 13.3 ; 7.5 \mathrm{G} / \mathrm{L} \pm 4.2 \mathrm{~GB}$ and $441.0 \mathrm{G} / \mathrm{L} \pm 564.7$. Conclusion: The JAK2V617F mutation had an interestin polycythemia vera value in diagnosis and can be systematic even in Sub-Saharan African.
\end{abstract}

Keywords: Polycythemia Vera, JAK 2 Changes, Lome (Togo)

\section{Introduction}

The polycythemia vera is a myeloproliferative syndrome resulting from the clonal expansion of a pluripotent hematopoietic stem cell. Originally an unregulated proliferation of predominantly myeloid tissue on erythroid associated with increased total volume of globular (VGT) [1], it was described for the first time by a French doctor, Louis Henri vera(1860-1936) on a special form of cyanosis accompanied by excessive and persistent hyperglobulie [2] The exact nature of the disorder of hematopoiesis in the origin of the disease remains unknown. However the existence of pathophysiological abnormalities multipotent stem cell are similar to those recognized in the other myeloproliferative disorders such as chronic myelogenous leukemia (CML), essential thrombocythemia (ET) and myeloid splenomegaly (SM). The age of onset is after 50 years with an average around 60 years. There is a maleprédomination. The evolution of polycythemia vera disease is slow, the survival after 10 years were not uncommon and evolves towards terminal myeloid splenomegaly or acute leukemia. In Europe and America, there is a frequency of 1 case per 10,000 people per year.

The pathogenesis of polycythemia vera has long remained unexplained, until spring 2005, when several groups of researchers have described the presence in myeloid cells of patients with recurrent and activating mutation in the Janus kinase gene JAK2V617F. This JAK2V617F mutation confers hypersensitivity cell lines and vis-a-vis independence of various cytokines including erythropoietin. Found in over $95 \%$ of cases of polycythemia vera, it opened the way for its molecular diagnostics. Especially the discovery of the mutation JAK2V617F [3] in polycythemia vera raises many questions. Few studies have been conducted in Africa $[4,5]$ 
in this context. In Togo a preliminary study was done in 2011 on the biological profile including research in the JAK2V617F first 15 patients followed for myeloproliferative syndromes in which JAK2 mutation was investigated systematically. [6] To complete this study we were interested in polycythemia in its epidemiological, clinical and laboratory to document the prevalence and describe the epidemiological, clinical and biological polycythemia vera in Campus Teaching Hospital of Lomé.

\section{Material and Method}

This study took place in Laboratories service of Campus Teaching Hospital of Lomé. Opened in 1988, this service welcomes patients from all backgrounds and provides consultation, care, teaching, and research and health educations for the treatment of sickle cell disease, hematological malignancies.

It was a descriptive study from May to October 2014witch inclued 13 patients regularly monitored at Campus Teaching hospital of Lomé since 2007 for polycythemia vera. All patients routinely underwent a complete physical examination, a biological exploration such as a blood count, a bone marrow biopsy, a balance sheet and a biochemical assay for serum erythropoietin.

The examination and clinical examination looking for signs of hyperviscosity (vascular or neurosensory signs: headache, dizziness, visual disturbances, paresthesia, venous thrombosis or arterial thrombosis) may require urgent treatment. The approach is based primarily on the positivity or not the search for the JAK2 (JAKV617F). The search for the JAK2 V617F mutation was performed at the molecular biology laboratory of the Henri Mondor Hospital in Creteil in France. Once PV is suspected through clinical signs and blood counts, the patient is routinely supported by the research of the mutation. The levies for research of mutation in France are done by vague for all $\mathrm{Ph} 1$ negative myeloproliferative neoplasmes. For PV, there were 2 levies waves ( 9 and 4 for each vague). For every research, after informed, a consent was signed and dated. A levy in four EDTA tubes of $2.5 \mathrm{ml}$ of venous blood was made and addressed to Henri Mondor at Créteil (France). The search of the JAK2 mutation was performed in all patients by PCR. It is a study of exon 14 of gene JAK2: quantitative study of the JAK2 gene (exon 14) by quantitative PCR (TAQMAN). The V167F mutation was investigated in neutrophils (Kit Ipsogen reference: MSPP-Ipsogen). The result is expressed as the number of Taqman cycles. The result is expressed as positive or negative research and as a percentage of $\mathrm{V} 617 \mathrm{~F} / \mathrm{WT}$ ratio. If the research was negative, a HRM study the JAK2 gene (exon 12) in neutrophils is performed with melting curve and existence of abnormality or not. In our study we used the diagnostic classification of myeloproliferative disorders of the World Health Organization (WHO) has [7, 8] Two major criteria (increase in hemoglobin and hematocrit in blood count or presence of the JAK2); two minor criteria (low blood erythropoietin hyperplasia or myeloid lineages in the bone marrow aspiration). The diagnosis of polycythemia vera is acquired when one has 2 major criteria and one minor criterion or one major criterion and 2 minor criteria.

Were not included in our study all patients were followed for polycythemia but have not benefited from the research of Jak2 or all patients with secondary polycythemia.

The data were entered into Excel and analyzed by the spike info 6.0 software.

\section{Results}

The unit of clinical hematology of Campus Teaching Hospital of Lomé has an active list of 3097 patients since 2007. Fifty-seven patients (1.84\%) were received in consultation for myeloproliferative syndrome in general which $34(1.10 \%)$ for CML with fusion transcript BCR-ABL and $23(0.74 \%)$ for $\mathrm{Ph} 1$-negative myeloproliferative disorders. Of these 23 patients there were 13 cases of polycythemia vera, 8 cases of essential thrombocythemia, 2 cases of myelofibrosis. The annual prevalence of the disease polycythemia vera is 2.16 new cases.

The average age of our patients was 46,7 ans (31 to 65 years). There were 9 male patients against 4 female or a sex ratio of 2.25. The slice of the most represented age was 50 years and over ( 5 cases) followed by the age groups of 40-49 years ( 4 cases) and 30-39 years ( 4 cases).

The histories of patients (Table 1) were represented by hypertension $(53.8 \%)$ followed by signs of hyperviscosity $(46.2 \%)$.

Table 1. Breakdown of patients history.

\begin{tabular}{lll}
\hline & Effectif & Pourcentage(\%) \\
\hline HTA & 7 & 53,8 \\
Hyperviscosity signs & 6 & 46,2 \\
Vein thrombosis & 3 & 23,1 \\
Smoking & 2 & 15,4 \\
AVC & 2 & 15,4 \\
Diabets & 1 & 7,7 \\
Herniated Disc & 1 & 7,7 \\
PVVIH & 1 & 7,7 \\
Hot flush & 1 & 7,7 \\
Dermatological lesions & 1 & 7,7 \\
Tetra-paresis & 1 & 7,7 \\
Varus Equine Congenital Feet Bot & 1 & 7,7 \\
Glaucoma & 1 & 7,7 \\
\hline
\end{tabular}

Most of our patients were detected during a checkup (23\% of cases) (Table 2). In our study, the most identified clinical signs are Headache (69.2\%) followed by paresthesia (30, 8\%) (Table 3).

The average hematocrit, mean hemoglobin levels, average number of white cells and platelets in patients with JAK2 mutation and those without JAK2 mutation are respectively: $62.7 \pm 4.4 \%(59,0 \pm 13.3 \%) ; 198 \mathrm{~g} / \mathrm{L} \pm 44 \mathrm{~d}(179 \mathrm{~g} / \mathrm{L} \pm$ 13.3); 9.8G/ $\mathrm{L} \pm 4.3$ (7.5G / $\mathrm{L} \pm 4.2) ; 630,4 \mathrm{G} / \mathrm{L} \pm 367.4$ (441,0G/L \pm 564.7$)$.

The JAK2 V617F mutation was positive in 9 patients $(69.2 \%)$ including 6 men and 3 women and negative in 4 patients ( 3 men and 1 woman). 
In our study, 11 patients $(84.6 \%)$ had a low serum erythropoietin levels.

The diagnosis of polycythemia vera was selected in 4 patients on the basis of two major criteria or a percentage of $30.7 \%$ of patients. In 4 other patients, the diagnosis was selected on the basis of a major and two minor criteria criterion or a percentage of $30.7 \%$. The diagnosis was retained in 3 patients based on two major criteria and one minor criterion or a percentage of $23,1 \%$. At last 2 patients, the diagnosis was selected on the basis of two major criteria and two minor criteria or a percentage of $15.4 \%$ of cases.

Table 2. Distribution of patients according to the circumstances of discovery.

\begin{tabular}{lll}
\hline & Number & Percentage (\%) \\
\hline Incidental finding & 3 & 23 \\
Dizziness and headache & 1 & 7,7 \\
OMI & 1 & 7,7 \\
Neck pain, back and left hemi thorax & 1 & 7,7 \\
Chance discovery during hospitalization & 1 & 7,7 \\
Thrust headache and hypertension & 1 & 7,7 \\
Chronic headache & 1 & 7,7 \\
Asthenia, headache and eye pruritus & 1 & 7,7 \\
Asthenia and Palpitation & 1 & 7,7 \\
Asthenia and et headache & 1 & 7,7 \\
Asthenia and Hot flush & 1 & 7,7 \\
Total & 13 & 100 \\
\hline
\end{tabular}

Table 3. Distribution of patients based on clinical sign.

\begin{tabular}{lll}
\hline & Number & Percentage (\%) \\
\hline Headache & 9 & 69,2 \\
Paresthesia & 4 & 30,8 \\
Dizziness & 3 & 23,1 \\
Tingling & 3 & 23,1 \\
Numbness & 3 & 23,1 \\
Visual disordes & 1 & 7,7 \\
Left Hemiplegia & 1 & 7,7 \\
Irregular BDC & 1 & 7,7 \\
\hline
\end{tabular}

\section{Discussion}

The strength of our study was not significantly representative. The hematology unit of the Campus Teaching Hospital of Lomé probably doesn't get all of Polycythemia Vera cases which may be diagnosed in Togo. It arises a general problem of accessibility for patients to adaptative hospitals and a problem of patient's adherence in long-term medical monitoring in Sub-Saharan African. However, this study showed that polycythemia are relatively frequent in hematology in Lomé and thus confirmed the diagnostic value of the JAK2 mutation research.

In our study, the average age of our patients followed for polycythemia vera was 46,7 ans was low compared to that of 63 years reported in the literature [9, 10]. Indeed Parasuraman S in there serie of 1309 patients, the average age was 62.5 years. [23]. As against our results are relatively similar to those of the series of Mahjoub S. et al [22] in Tunisie who find a average age at 53 years in a cohort of 22 patients.

Should the generally low life expectancy in sub-Saharan Africa explain the early onset of polycythemia? We do not exclude the possibility that advanced age patients didn't consult in adapted health facilities. A larger sample size will greatly probabily the age average in our African series.

In $69.2 \%$ of cases, our patients were male ( 9 men and 4 women) with a sex ratio of 2.25 . This result is similar to that found in several studies $[11,12,13]$ who found a male with 8 men to 1 woman.

However our results are different from those of S Mahjoub [22] who found a sex-ration at 0.8 . We can not give a clear explanation to this difference in sex. Here again we can evoke but not confirm that the difference could be due to the smalest of our serie. Twenty-three percent of patients were detected during a checkup. In a study by Cassinat [14], polycythemia vera was also discovered incidentally in $46.11 \%$ of cases. These systematic discovery circumstances of PV, both in our study and in the literature [18] imply the importance of achieving blood counts routinely in our populations.

These results are explained by the fact that polycythemia vera remains an unknown disease in our communities.

The most identified clinical signs were headache $(69.2 \%)$ followed by skin paresthesia (30.8\%).

Moliterno et al [15] in their series had reported headache $(63.2 \%)$ and skin érythroses $(70.4 \%)$ as the most common clinical signs of patients.

These results show that the primary polycythemia go about most often manifests itself by headache.

The proportion of the JAK2 mutation positivity during polycythemia vera in our study $(69.2 \%)$ is lower than the literature data. Indeed, Ayad et al [4] in Egypt reported $81.4 \%$ positivity, whereas Benmoussa et al [5] in Morocco recorded $89.4 \%$ for the workforce of 246 and 88 cases of myeloproliferative disorders. Outside of Asian studies [16, 17], the positivity proportions are identical to those of North Africa [4, 5], the Western series reported a positivity rate of 95\% during the Polycythemia Vera $[18,19]$.

A recent Japanese study found also that 93, 2\% of polycythemia patients had the mutation [24] However, Mahjoub S. [22] in his series of 24 pateints found a rate of $64.4 \%$. His results are very similar to our rates. Again, the sample size it would play a decisive role?

Eleven (11) patients or $84.6 \%$ of our patients had a low erythropoietin levels.

In a study by Mirza and [20] the erythropoietin level was low in $97.3 \%$ of cases.

The average value of hemoglobin in JAK2 positive patients was $19,8 \mathrm{~g} / \mathrm{dl} \pm 4.4$ against $17,9 \mathrm{~g} / \mathrm{dl}$ for those with JAK2 is negative.

In the study in Turkey Mutlu et al [21] the average value of hemoglobin of patients with polycythemia who had the JAK2 mutation was positive de15.56g / dl \pm 3.01 contre $14.22 \mathrm{~g} / \mathrm{dl} \pm 3.0719$ among those with JAK2 is negative.

Similar results were found by several authors who concluded that the presence of this mutation may play a role in the development of vascular complications. [22, 25, 26] These results show that Jak2V617 mutation would affect the severity of signs and occurrence would be a factor of progressive complications. 


\section{Conclusion}

The primitive polycythemia vera is relatively common in our communities. It is important to diagnose the disease as early as possible in view of its thrombotic complications.

Even in developing countries, the confirmation of the molecular biology diagnostic certainty vera disease is possible.

These results illustrate a North-South collaboration and effective copy that has improved the diagnosis, treatment and prognosis of primary polycythemia vera in sub-Saharan Africa.

\section{References}

[1] PaHL. Towards a molecular understanding of polycythemia rubravera. Eur J Biochem 2000; 267: 3395-401.

[2] Kralovics R, Guan Y, Prchal JT. Acquired uniparentaldisomy of chromosome $9 \mathrm{p}$ is a frequent stem cell defect in polycythemia vera. Exp Hematol 2002; 30: 229-36.

[3] Vainchenker W, Casadevall N. «JAK» a dit: c'est un syndrome myéloprolifératif. Hématologie2006; 12: 4.

[4] Ayad MW, Nafea D. Acquired mutation of the tyrosine kinase JAK2V617F in Egyptian patients with myeloid disorders. Genet Test Mol Biomarkers 2011; 15: 17-21.

[5] Benmoussa A, Dehbi H, Fehri S, Quessar A, Nadifi S. JAK2V617F mutation in Moroccan patients with myeloproliferative disorders: contribution, diagnosis and therapeutic prospects. Pathol Biol (Paris) 2011; 59: e89-92.

[6] Padaro E, Agbetiafa K, Kueviakoe IMD, Layibo Y, Segbena $A Y$, Sanogo $I$ et al: Syndromes myéloprolifératifs «Philadelphienégatif» et mutation JAK2V617F:étude des 15 premiers casayant bénéficié de cette recherche au Togo. Ann BiolClin2012; 70 (5): 591-4.

[7] Vardiman JW, Harris NL, Brunning RD. The World Health Organization (WHO): classification of myeloid neoplasms. Blood2002; 100: 2292.

[8] Télleri A, Vardman JW. Classification and diagnosis of myeloproliférativeneoplasme: the 2008 World Health Organisation and point of car diagnostic algorithms. Leukemia 2008: 22 ; $14-22$.

[9] Kiladjan JJ, Gardin C, Renoux M, Bruno F, Bernard JF. Longterm outcomes of polycytttthemiavrea patients treated with pipobroman as initial therapy. Hematol J 2003; 4: 198-207.

[10] Kiladjian JJ, Cassinat B, Chevret S, Turlure P, Cambier N, Roussel $M$, et al. Pegylated interferon-alfa-2a induces complete hematologic and molecular responses with low toxicity in polycythemia vera. Blood 2008; 112: 3065-72.

[11] Kiladjian JJ, Chomienne C, Fenaux P. Interferon-alpha therapy in bcr-abl-negative myeloproliferative neoplasms. Leukemia 2008; 22: 1990-8.

[12] Kiladjian JJ. Diagnostic et traitement de la thrombocytémie primitive. Rev Prac2005; 55: 1671-9.

[13] Levine RL, Wadleigh M, Cools J, Ebert BL, Wernig G, Huntly $B J$, et al. Activating mutation in the tyrosine kinase JAK2 in polycythemia vera, essential thrombocythemia, and myeloid metaplasia with myelofibrosis. Cancer Cell 2005; 7: 387-97.
[14] Cassinat B. Laguillier C. Gardin C. de Beco V. Burcheri S. Fenaux $P$. et al. Classification of myeloproliferative disorders in the JAK2 era: is there a role for red cell mass? Leukemia 2008: 22: 452-3.28-.

[15] Moliterno AR. Spivak JL Posttranslation processing of the Thrombopoietin receptor is impaired vera. Blood 1999; 94: 2555-61.

[16] Sazawal S, Bajaj J, Chikkara S, Jain S, Bhargava R, Mahapatra $M$, et al. Prevalence of JAK2 V617F mutation in Indian patients with chronic myeloproliferative disorders. Indian J Med Res 2010; 132: 423-7.

[17] Yuan LY, Li H, Chen GA, Ji DX, Gao LL, Rong JP, et al. Incidence of JAK2V617F mutation in myeloproliferative diseases and its clinical significance. Zhejiang Da Xue Xue Bao Yi Xue Ban 2010; 39: 202-6.

[18] Knoops L, Hermans C, Ferrant A, Constantinescu SN. Clinical implications of JAK2 mutations in myeloproliferative disorders. Acta Clin Belg 2008; 63: 93-8.

[19] Fiorina G, Luciana T, Maria LM, Maurizio M, Giovanna P, Angela $A$. Thrombocythemia and polycythemia in patients younger than 20 years at diagnosis: clinical and biologic features, treatment, and long-term outcome. Blood, 8 March 2012 _ Vol 119, Num 10 p9.

[20] Mirza AM, Ezzat S, Axelrad AA, Insulin-like gzowth factor binding protein-1 is elevated in patients with polycythemia vera and stimulates erythroid burst formation in vitro. Blood 1997; 89: 1862-9.

[21] Mutlu K, Tahsin Y, Vildan O, Fahir O, Ridvan A, Murat B et al. Evaluation of the JAK2-V617F gene mutation in Turkish patients with essential thrombocythemia and polycythemia vera. Mol Biol Rep (2012) 39: 8663-8667 Doi 10.1007/s11033-012-1721-x; 1-5 p.

[22] Mahjoub S, Baccouche H, Sahnoun M, Kaabi H, Manai Z, Slama H, Ben Romdhane N. The JAK2 mutation in myeloproliferative neoplasms: A predictive factor of thrombosis. Tunis Med. 2015 Jul; 93(7): 474-7.

[23] Parasuraman S, DiBonaventura M, Reith K, Naim A, Concialdi K, Sarlis NJ. Patterns of hydroxyurea use and clinical outcomes among patients with polycythemia vera in real-world clinical practice: a chart review. Exp Hematol Oncol. 2016 Feb 1; 5: 3.

[24] Mutationsmasahirookabe, Hiroki Yamaguchi, Kensuke Usukib, Yutaka Kobayashi, Eri Kawatac, Junya Kuroda, Shinya Kimura et al Clinicalfeatures of Japanese polycythemia vera and essential thrombocythe mia patients harboring CALR, JAK2V617F, JAK2Ex12del, and MPLW515L/K mutations. Leukemia Research 40 (2016) 6876.

[25] Radia D, Geyer HL. Management of symptoms in polycythemia vera and essential thrombocythemia patients. Hematology Am Soc Hematol Educ Program. 2015 Dec 5; 2015(1): 340-8.

[26] Okabe M, Yamaguchi H, Usuki K, Kobayashi Y, Kawata E, Kuroda J, Kimura $\mathrm{S}$ et al. Clinical features of Japanese polycythemia vera and essential thrombocythemia patients harboring CALR, JAK2V617F, JAK2Ex12del, and MPLW515L/K mutations. Leuk Res. 2016 Jan; 40: 68-76. 